\title{
Case study on the environmental impacts of the design, construction and operation of a storage, treatment, utilization (recovery/recycling) and/ or waste disposal end of electrical and electronic equipment (WEEE) in the company Recover SAS NEIVA
}

\begin{abstract}
Summary
For the evaluation of the environmental impact of the design, construction and operation of a plant storage, treatment, utilization (recovery/recycling) and/or disposal of waste electrical and electronic equipment (WEEE) for the company to recover Neiva SAS game the provisions of environmental legislation in the Republic of Colombia and studies on the subject. Then a diagnosis was made of environmental zoning of the area of direct influence (Barrio Reinaldo Matiz); Based on the characterization of strategic development plans; carried out the environmental impact assessment by reference to the methodology proposed by Fernandez, ${ }^{1}$ for environmental management zoning exclusion areas were established, Environmental impacts associated with the implementation of the project had a rating of compatible severe, however, all negative impacts had a maximum rating of moderate, this shows the lesser degree of alteration that generates the design, construction and operation of a plant storage, processing, utilization (recovery/recycling) and/or disposal of (WEEE) given the characteristics of the area where take place, so the salient negative impacts are pollution particulate matter (air) pollution emission (air), solid waste pollution (soil), and positive are proper handling WEEEs (waste), training,awareness and acceptance of the community for a better management of RAEEs (sociocultural) and conservation of the environment (sociocultural).
\end{abstract}

Keywords: informal recycling, environmental assessment, special waste, environmental management alternatives
Volume 7 Issue I - 2020

\section{Nina Isabella Rodriguez Sanchez, Yerson Camilo Rivera Garcia \\ Undergraduate student of Environmental Engineering program, Navarra University Foundation, Colombia}

Correspondence: Nina Isabella Rodriguez Sanchez, Undergraduate student of Environmental Engineering program, Navarra University Foundation. Neiva - Huila, Colombia, Email nina.rodriguz@uninavarra.edu.co, isabelta-1504@hotmail.com

Received: September 16,2019 | Published: January 24, 2020
Abbreviations: EEE, electrical and electronic equipment; WEEE, waste disposal end of electrical and electronic equipment; MAVDT, ministry environment, housing and territorial development

\section{Introduction}

Electrical and electronic equipment (EEE) are products which are present in the daily lives of almost all citizens, it is unthinkable in contemporary society does not have a cell phone, television, washing machine, among others, production and consumption electrical appliances or devices, electronic, computer and combinations thereof extends reason for the current socioeconomic system that focuses on unlimited consumption and production levels of control technology easily accesible. ${ }^{2}$ These devices are constructed by a combination of parts or elements to function need electric current or electromagnetic fields that perform a number of jobs or certain functions and at the time in which their owners think they are not profitable, they become eliminated becoming RAEEs. ${ }^{2}$ This situation in terms of production releases uncontrolled exploitation of raw materials, energy consumption mostly from fossil sources and waste generation, threatening the environmental sustainability of the planet and can affect the health and lives of all its inhabitants.
Faced with the theme The Ministry of Environment, Housing and Territorial Development of the Republic of Colombia ${ }^{3}$ published the national policy of sustainable production and consumption with the aim of guiding the changing patterns of production and consumption towards environmental sustainability and contributing the competitiveness of enterprises and the welfare of Colombian society. Since 2010 the construction and operation of installations for the purpose storage, processing, utilization (recovery and recycling) or disposal of WEEE is subject to environmental licensing (p.1). In the same way the Congress enacted Law 1672 on July 19, 2013; "Why the guidelines are established for the adoption of a public policy of comprehensive management of WEEE and other provisions" (p.1). This law establishes the extended responsibility of the producer as a guiding principle of the policy and assigns duties and responsibilities to all players in the chain as manufacturers and importers, traders, consumers and managers of WEEE establishing obligations to the various entities that make the national government, environmental authorities and local authorities.

This mobilization in public policies aimed at developing social and environmental programs that promote the understanding of the proper management of electronic waste, conservation and sustainable use of biodiversity in Colombia, so that citizens understand that living with 
a healthy environment ensures the preservation of communities, also to take action to remedy the damage already caused with the support of government agencies in their region building action plans and management plans that will contribute to the harmonious development of this área by Minambiente. Public policies seek to educate citizens on the final disposition of RAEEs but also focuses on regular and factories, businesses waste collection or toiletries and other industries give definitive solution to this need, the result of these policies in the area has been regulating the design, construction and operation of plants storage, processing, utilization (recovery/recycling) and/or disposal of WEEE, prior environmental impact.

So that the content herein was developed taking into account the terms of reference for the environmental impact assessment for design, construction and operation of a storage plant, treatment, utilization (recovery/recycling) and/or disposal of RAEEs dictated by the Autonomous Corporation of Alto Magdalena (CAM), making the description of the classification of waste electrical and electronic equipment, in addition, the environmental characterization of the area of influence of the project, considering the biotic, abiotic and socioeconomic means. Through the EIA (Environmental Impact Study) effects were estimated on the fauna, flora, soil, water, air, climate, landscape and the role of ecosystems in the area of development of the project.

\section{Materials and methods}

The content of the study was prepared under the logic of conservation and sustainable use of natural resources, developing alternatives necessary to prevent, mitigate any negative impacts that can generate future project. The focus of the methodology is defined as a qualitative, this research is aimed at understanding the phenomena, exploring them from the perspective of the participants in a natural environment and in relation to its context, is an approach that is selected when the purpose is to examine how individuals perceive and experience phenomena around them, deepening their views, interpretations and meanings. ${ }^{5}$ The qualitative approach by Taylor \& Bogan ${ }^{4}$ broadly be defined as research that produces descriptive data, such as the words of the people, spoken or written, and observable behavior, this approach allows researchers to understand and develop concepts based on data patterns, do not collect data to test hypotheses or preconceived theories but follow a flexible research design, vaguely formulated questions, understand the context and people under a holistic perspective. This project specifically proceeded to the assessment of environmental impacts, where a qualitative assessment considering the nature of the impact, as well as criteria considered as intensity, extent, time, persistence, probability, synergy was performed. Qualitative approaches are a kind of plan of exploration and emerging understanding and are appropriate when the researcher is interested in the meaning of the experiences and human values at the point of internal and individual view of people and the natural environment in which the studied phenomenon occurs, and when we look for a close view of the environmental impacts of RAEES.

The methodology was developed in three main phases which are:

a. Stage I: Exploratory: Data collection and review of documentation collecting information necessary theoretical was conducted for developing the theoretical framework and the regulatory framework; the latter was essential for the proper assessment of the environmental impacts of the project.

b. Stage II: Experimental and development of the Project. To develop this stage of the evaluation a theoretical situational analysis which involved the recognition of the company was conducted. It also made use of sources of information suitable for characterizing the biotic, abiotic and socioeconomic respectively, mainly studies media made by project Universities, as well as entities such as the Institute of Hydrology, Meteorology and Environmental Studies (IDEAM) ${ }^{6}$ the Ministry Environment, Housing and Territorial Development (MAVDT), ${ }^{7}$ the Colombian Corporation for Agricultural Research (CORPOICA), the Regional Autonomous Corporation of the Alto Magdalena (CAM), the National Administrative Department of Statistics (DANE), the Research Institute of Biological Resources Alexander von Humboldt (IAvH), the Municipal Mayor of Neiva, among others.

c. Stage III: Evaluation of potential environmental impacts that can build the Project: In this phase they were identified and evaluated impacts through the matrix method corresponding to the methodological guide for evaluating the environmental impact of Fernández ${ }^{1}$ which are located on the horizontal axis activities the project which can generate in connection with the components of the medium and its characteristics on the vertical axis. Once identified impacts, we proceeded to the evaluation of environmental impacts, where a qualitative assessment considering the nature of the impact, in addition to criteria considered as intensity, extent, term persistence probability, synergy, accumulation, effect frequency was performed and recoverability. After assessed the impact its importance was determined and classified according to the range to identify it as consistent, moderate, severe or critical. Subsequently, an integrated, biotic and socioeconomic means in relation to abiotic environmental assessment analysis was performed. ${ }^{7}$

d. Stage IV: Screening of prevention and mitigation alternatives: Set detailed alternatives for prevention and mitigation for activities generated in the stages of the project, which is formulated from an environmental assessment and are aimed at preventing and mitigating the negative environmental impacts that are caused by the development of a project, work or activity. ${ }^{8}$

\section{Results and discussion}

The environmental impact assessment is a procedure aimed at the identification, prediction and interpretation of environmental impacts a project, work or activity will produce if carried out, projecting the prevention, correction and evaluation of them, this in purpose of being accepted, modified or rejected by the competent environmental authorities. ${ }^{9}$ To start, all activities performed in each stage of the project, then the aspects were analyzed for each of the activities and identify potential impacts that may cause such steps are described. Once environmental impacts identified, we proceeded to the evaluation of the same, where a qualitative assessment considering criteria such as the nature of the impact intensity, extent, term persistence probability, synergy, accumulation, effect, periodicity and recoverability was performed; as well as a quantitative assessment assigning values to each of the aforementioned criteria. ${ }^{1}$ Assessed the impact its importance was determined and classified according to the range to identify it as compatible moderate, severe or critical, in parallel was performed an analysis integrated abiotic, biotic and socioeconomic means, in relation to environmental assessment, where they defined the different components. ${ }^{10}$ 
To prepare the matrix will be assigned ponderativos values to each component, depending on how affected perceived during the project, then these values were considered between the impacts affecting the respective component considering the methodology described above. Equally important values were changed at the discretion of the authors according to the activities and the impact of these on the manifestation of the assessed impact. All of the above was applied to each stage of the project: design, construction and operation; where in the design stage five (5) activities were identified with six (6) aspects and eight (8) environmental impacts identified; similarly, the construction stage four (4) activities, twelve (12) contemplated aspects and fifteen (15) environmental impacts identified; finally in the stage of operation, nine (9) established activities, and nineteen (19) issues were identified and twenty three (23) environmental impacts; for a total of forty-six (46) environmental impacts. Of the 46 environmental impacts, only four (4) had a maximum score of severe corresponding to contamination by particulate matter (air) pollution emission gases (air), solid waste pollution (ground), which means that involvement of these impacts requires recovery conditions and the average recovery time is needed over an extended period. Given that these impacts are generated in the construction phase by transport activity material and in the operation phase by activities such as disassembly, decontamination and trituration WEEEs, these impacts can be prevented and mitigate, at the time of to start the project activities, applying each of the alternatives proposed in stage IV.

Emphasizing four (4) impacts significant, it should be noted that one of them identified at the stage of construction activities such as material transport and adaptation of space, given that these generate activities, particulate material, compacting the ground, besides air emissions by using fuel machinery, this causing air pollution, but considering that the most affected is by using fuel generating gaseous pollutants, but in return can be said that this generation is not constant if not only when end stage of construction is for them to their highest rating it was severe. Likewise, the four (4) impacts identified as severe, three (3) of them are presented in the operation stage which is where the project start and run for storage, treatment and disposal of WEEE, for them is that for activities such as take apart, decontamination and trituration WEEEs, aspects are presented as dumping of potentially harmful substances and if not in a place appropriately adapted to the technical standards, it can generate impact rating severe resulting from pollution to the ground by dumping and infiltration. Similarly, for the same activity at the time of disassembling equipment emissions possibly dangerous gases are generated, thus causing pollution atmospheric emissions, Of the 46 environmental impacts evaluated, thirty-four (34) were rated moderate, this means that most of the impacts identified for this project does not have a high involvement to the environment, therefore, it is not required internships generated to prevent or mitigate the same.

Finally, eight (8) of the forty-six (46) environmental impacts are low, which means that the impact of these is irrelevant to the aims and objectives of the project in question. The foregoing shows that the degree of disturbance that generates the design, construction and operation of a storage plant, treatment, utilization (recovery/ recycling) and/or disposal of (WEEE), is more positive than negative, since the not alter or modify impacts to the environment, if not on the contrary, this project contributes to the generation of new knowledge, proper management of WEEE and to preserve the life of landfills. After assessed the impact depending on their importance and classification, an integrated abiotic, biotic and socioeconomic regarding environmental assessment, as shown in the following table analysis was performed (Table 1). All impacts identified and evaluated were grouped into three pillars: socioeconomic environment biotic, abiotic environment and because of this we can see that the 4 severe impacts that gave assessing the impact matrix, only affect the abiotic environment in the component air and soil, taking into account that these are not of great concern, and that can prevent and mitigate following the proposed alternatives in this project. One of the two impacts most significant identified as pollution of the soil dumping of oils, lubricants or other liquids present in WEEEs causing impairment to the abiotic environment in the use of the ground, considering that these liquids presents hydrocarbon derivatives also contain a highly dangerous and time to make contact with the environment, may lose fertility, soil favoring filtration contaminating groundwater and can reach rivers pollute lakes among others, altering the ecosystem and life of living things.

Table I Level of environmental impact expressed in colors and associated qualifications thrown in the matrix ElA evaluated criteria

\begin{tabular}{llll}
\hline Medium & Component & Negative impacts & Score \\
\hline Abiotic & Floors & Compaction of the soil & 25 \\
& Reduced soil infiltration & 25 \\
& Alteration of biogeochemical cycles soil & twenty \\
& Alteration of the floor by changing pH & 25 \\
& Pollution of the soil dumping of oils, lubricants or other liquids present in & 55 & twenty \\
WEEEs & twenty \\
& Loss of soil coverage & 30 \\
& Increased erosion processes & 30 \\
& Solid waste generation for equipment removal activities & 25 \\
& Solid waste generation by demolition activities for mining equipment & 30
\end{tabular}

Citation: Sanchez NIR, Garcia YCR. Case study on the environmental impacts of the design, construction and operation of a storage, treatment, utilization (recovery/recycling) and/or waste disposal end of electrical and electronic equipment (WEEE) in the company Recover SAS NEIVA.J Appl Biotechnol Bioeng. 2020;7(I):27-32. DOI: 10.15406/jabb.2020.07.00212 
Case study on the environmental impacts of the design, construction and operation of a storage, treatment, utilization (recovery/recycling) and/or waste disposal end of electrical and electronic equipment (WEEE)

\begin{tabular}{|c|c|c|c|}
\hline Medium & Component & Negative impacts & Score \\
\hline & Geomorphology & Affectation of the landscape & twenty \\
\hline & Air & Particulate material shift staff & fifteen \\
\hline & & $\begin{array}{l}\text { Emission of pollutant gases (neon, argon, mercury gas) released by faulty } \\
\text { equipment }\end{array}$ & 60 \\
\hline \multirow{2}{*}{ Biotic } & & Affectation of the soil fauna & 27 \\
\hline & Flora & displacement mulched & 25 \\
\hline \multirow{4}{*}{$\begin{array}{l}\text { Economic } \\
\text { partner }\end{array}$} & & Generation of occupational diseases & 24 \\
\hline & & Training of personnel for management of WEEE & twenty \\
\hline & Costs & Cost adequacy storage spaces & twenty \\
\hline & & Storage space occupation & 26 \\
\hline
\end{tabular}

Table 2 Alternatives and corrective measures in the management of WEEE

\begin{tabular}{|c|c|c|}
\hline Process & Alternatives & Corrective measures \\
\hline \multirow[t]{3}{*}{ Reception } & $\begin{array}{l}\text { Categorization of WEEE from } \\
\text { the source in the categories } \\
\text { described above }\end{array}$ & $\begin{array}{l}\text { Inform and train the staff in general against the provision and delivery of devices } \\
\text { derecognized }\end{array}$ \\
\hline & $\begin{array}{l}\text { Have a website or collection } \\
\text { center suitable for receiving } \\
\text { devices and elements } \\
\text { derecognized }\end{array}$ & $\begin{array}{l}\text { Adequacy of spaces for the collection and temporary storage, taking into account the } \\
\text { physical characteristics of the point. }\end{array}$ \\
\hline & $\begin{array}{l}\text { Establish the minimum } \\
\text { conditions for reception of } \\
\text { WEEE }\end{array}$ & $\begin{array}{l}\text { WEEE needs to be received in a position that can be stored safely and transferring to } \\
\text { this should refer to storage conditions and packaging described above }\end{array}$ \\
\hline \multirow[t]{3}{*}{$\begin{array}{l}\text { internal and } \\
\text { external } \\
\text { transport }\end{array}$} & $\begin{array}{l}\text { The removal or transfer } \\
\text { must be done provided } \\
\text { transportation meets the } \\
\text { security conditions required }\end{array}$ & $\begin{array}{l}\text { Perform the evaluation to the physical and mechanical condition of the vehicle assigned } \\
\text { for this purpose }\end{array}$ \\
\hline & $\begin{array}{l}\text { Elements to the location within } \\
\text { the vehicle safely and optima of } \\
\text { WEEE }\end{array}$ & $\begin{array}{l}\text { Adapt the vehicle so that WEEE are transported safely and optimally (pallets, boxes and } \\
\text { wooden or metal ropes or ties) }\end{array}$ \\
\hline & $\begin{array}{l}\text { Access points and adequate } \\
\text { logistics }\end{array}$ & $\begin{array}{l}\text { Ramplas implement, access roads and appropriate collection points for easy loading or } \\
\text { unloading of WEEE }\end{array}$ \\
\hline \multirow[t]{4}{*}{ Storage } & $\begin{array}{l}\text { Classification of WEEE in } \\
\text { Categories }\end{array}$ & identify, select and rank within the parameters of this work categorization \\
\hline & $\begin{array}{l}\text { Establish exclusive sites for } \\
\text { WEEE. }\end{array}$ & $\begin{array}{l}\text { Adapt spaces or deploy if the conditions do not exist and physical, technical and } \\
\text { environmental }\end{array}$ \\
\hline & $\begin{array}{l}\text { Equipment and tools for the } \\
\text { collection and Internal logistics }\end{array}$ & Implement equipment and tools for logistics, control and labeling of WEEE. \\
\hline & $\begin{array}{l}\text { Conditions or Temporary } \\
\text { Storage Collection }\end{array}$ & Adequacy of pallets, materials for coating WEEE for later disposl metal boxes, containers. \\
\hline
\end{tabular}

Citation: Sanchez NIR, Garcia YCR. Case study on the environmental impacts of the design, construction and operation of a storage, treatment, utilization (recovery/recycling) and/or waste disposal end of electrical and electronic equipment (WEEE) in the company Recover SAS NEIVA. J Appl Biotechnol Bioeng. 2020;7(I):27-32. DOI: 10.15406/jabb.2020.07.00212 
Table Continued

Process Alternatives Corrective measures

Use and recovery

Smelting and recycling

Final disposition
Incineration

Safety padding
Adapting equipment and areas can be made proper and common recycling casting of ferrous metals by means of technical unpacking.

Recover, nonferrous noble metals contained in the printed circuit boards and other electrical and electronic waste through thermal or chemical processes.

Incinerators under high technical standards that allow recovery of the energy value in the form of electrical energy and avoid contamination of the environment by air emissions through decontamination control systems and emissions.
Include the final disposition of the ashes in secure landfill.

Arrangement of the remaining fractions in recycling and incineration processes, to the like components containing hazardous substances that have no suitable use processes.

For non-usable materials identified during the steps of unpacking such as dust accumulated in the equipment, decals and bonded paper to, packing materials, tires and rubber, they may be delivered to the company toilet area for disposal in common sanitary landfill.
A time to begin the operational phase, which is already beginning to the project function as such activities are presented as take apart, decontamination and shredding RAEEs, which if not given proper handling can cause emissions of potentially dangerous gases, causing atmospheric pollution emissions affecting air resource, but its maximum score was severe and that this impact can be prevented by installing gas control equipment. Bearing in mind that if maximum impact rating is not as critical could prevent or mitigate if not it would be corrected because its involvement could be higher. The most important positive impacts are related to the increase of the economy, job creation, acceptance of new knowledge by the community, training, awareness for better management of RAEEs (sociocultural) and conservation of the environment (sociocultural); these are related to the operation and the benefits it brings. Economic revitalization, meanwhile, takes place on the purchase of products and services in the different stages of the project, representing a favorable point for the local economy (Table 1). Having performed the appropriate qualitative and quantitative assessment of environmental impacts, this chapter has discussed alternatives management activities necessary to implement those impacts that representative (Table 2) were considered. Detailed set of activities, which are formulated from an environmental assessment and are aimed at preventing and mitigating the negative environmental impacts that are caused by the development of a project, work or activity. ${ }^{8-33}$

\section{Conclusion}

a theoretical situation assessment was performed by collecting secondary information necessary for developing the theoretical framework which includes information of the company concerned, the generation of waste globally classification WEEEs from different references, besides the regulatory framework; which it was essential for the proper assessment of the environmental impacts of the project. Observed in gathering information even when the national government has joined efforts to ensure that environmental legislation is complied with, there is a lack of monitoring and control of the various actors involved in the management of WEEE. Was identified and aspects evaluated and environmental impacts for each of the activities resulting from the stages of design, construction and operation of a storage plant, treatment, utilization (recovery/recycling) and/or disposal of waste electrical and electronic (WEEE) for the company RECOVER NEIVA SAS, using the matrix of environmental impact assessment (EIA) of Vicente Conesa Fernández (2000), which allowed to calculate the importance of each of the impacts generated by each of the activities evaluated. The positive impacts identified with this project are related to the increase of the economy, job creation, acceptance of new knowledge by the community, training for proper management of WEEE (sociocultural) and conservation of the environment (sociocultural).

a proposal for alternative prevention and mitigation was established for each of the processes of the project, taking into account the principles of sustainable development, and generate solutions to environmental impacts obtained as severe rating and moderate in project design, construction and operating a plant storage, processing, utilization (recovery/recycling) and/or disposal of WEEE, 
allowing develop strategies suitable for control and management, and implementing the standards containing the technical conditions for execution.

\section{Acknowledgments}

We thank the Navarra University Foundation, in addition to the director of the Environmental Engineering Program Leidy Johana Sanchez Diaz, for his support and motivation; also the collaboration of public and private entities that were part of the study, for Glad we provided information for the development of this research.

\section{Conflicts of interest}

No conflicts to declare.

\section{Funding}

None.

\section{References}

1. Fernandez VVC. Methodological guide for environmental impact assessment. Madrid; Spain: Editorial Oxford University Press; 2000.

2. WIPO. Patent Landscape Report on E-waste Recycling Technologies. 2013.

3. Ministry of Environment, Housing and Territorial Development Technical Guidelines for the management of waste electrical and electronic equipment. 2011.

4. Taylor S, Bogdan R. Introduction to qualitative research methods. Barcelona; Spain: Editorial Paidos; 1986.

5. Hernandez R, Fernández C, Baptista P. Investigation methodology. Mexico City; Mexico: Editorial Mc Graw Hill; 2014.

6. Institute of Hydrology, Meteorology and Environmental Studies of Colombia. 2010.

7. Ministry of Environment, Housing and Territorial Development Application Guide Economic valuation. 2012.

8. Ministry of Environment of the Republic of Colombia. Environmental Guide for water systems. 2002.

9. Bañón SP. Design of a plant for the treatment of WEEE. 2009.

10. Child AJ, Bermudez GS. Duke DM. Model for the integrated management of WEEE (waste electrical and electronic equipment) in the ARB (Association of Recyclers of Bogotá). 2015.

11. Mayor of Neiva. General information. 2019.
12. Angel L. Neiva service portfolio SAS recover. Neiva. 2018.

13. Baldé CP, Wang F, Kuehr R., et al. The overall e-waste monitor 2014, United Nations University, IAS - SCYCLE, Bonn, Germany; 2015.

14. Bioethics: Bridge to the Future. In: Van Rensselaer Potter, Englewood Cliffs, editors. NJ: Prentice-Hall Pub; 1971.

15. Hood MA, Drane, J. Bioethical approach of the Environment Bioethikos Journal. 2014;8(1):46-52.

16. Congress of Colombia. Published in Official Gazette No. 41146. 1993.

17. Congress of Colombia. National Decree 1077; 1995.

18. Congress of Colombia. 2006.

19. Congress of Colombia. Published in Official Gazette No. 48,102; 2011.

20. Congress of Colombia. Law 1672 of 19 July 2013. Published in Official Journal cxlix year. N. 48856; 2013.

21. Regional Autonomous Corporation of the high Magdalene- CAM. 2019.

22. National Planning Department. National Development Plan 20142018: All for a new country. 2015.

23. Diaz RL. Study of strategic development plans. 2011.

24. Eco Computo. Mission and vision.

25. Fecoc. Total $\mathrm{CO}_{2}$ emissions calculated. 2015.

26. Gaiavitare. Mission and vision. 2019.

27. Gecoraee. Company characteristics. 2019.

28. Martinez J. Guide to Hazardous Waste Management - Fundamentals. Coordinating center for the Basel Convention for Latin America and the Caribbean. 2005.

29. Martinez SM. Analysis of the generation and disposal of waste electrical and electronic equipment RAEE'S household in the municipality of Yopal (Casanare), (Masters Thesis). University of Manizales; 2015.

30. Ministry of Environment of the Republic of Colombia. Contingency Plan (PDC); 2016.

31. Ministry of Environment VyDT. General methodology for Submission of Environmental Studies. 2010.

32. Ministry of Environment, Housing and Territorial Development National policy for the integrated management of waste electrical appliances. 2017.

33. Rivers OJF. Management of waste electrical and electronic equipment (WEEE) in the city of Armenia, Quindio (master's thesis). University of Manizales; 2016. 